\title{
Characterization of Injuries in Male and Female Ultimate Frisbee Players at the Elite Club-Level
}

\author{
Kevin J Khoo, BS ${ }^{1}$, Joshua M Gellert, DPT, SCS ${ }^{2}$, Mia S Hagen, MD ${ }^{3}$ \\ 1 The University of Washington School of Medicine, ${ }^{2}$ Sports Medicine Center, The University of Washington, ${ }^{3}$ Department of Orthopedics and Sports \\ Medicine, The University of Washington \\ Keywords: gender, prevention, epidemiology, prevalence
}

https://doi.org/10.26603/001c.21176

\section{International Journal of Sports Physical Therapy}

Vol. 16, Issue 2, 2021

\section{Background}

Ultimate Frisbee is a rapidly growing sport played in all levels of competition in men's, women's, and coed divisions. Despite widespread popularity, there remains a lack of research on injury risk and prevalence during a season.

\section{Purpose}

To determine the prevalence of injuries among elite club-level men and women Ultimate Frisbee players and to identify elements associated with injury during a single season.

\section{Study Design}

Descriptive epidemiological study.

\section{Methods}

Voluntary preseason and postseason online surveys were distributed to local elite club-level Ultimate teams in 2019. Surveys assessed players' lifetime Ultimate-associated injury history, injury status, training regimen, and other related elements.

\section{Results}

Fifty-seven and 84 players were eligible to complete the preseason and postseason surveys, respectively. Prior to the 2019 season, $97 \%$ of female respondents and $100 \%$ of male respondents reported a previous Ultimate-related injury in their career, with all reporting a prior lower extremity injury. During the 2019 season, $56 \%$ of respondents reported being injured, and $12 \%$ missed one month or more of the season, with $88 \%$ of injured players reporting a lower extremity injury. Men reported more ankle and calf injuries than women, and there was a strong negative correlation between time missed due to injury during the 2018 season and the number of days per week spent weight-training and accumulated training.

\section{Conclusion}

There is a high prevalence of lower extremity injury among elite club-level Ultimate players during a single season and pervasive lower extremity injury history may contribute to high injury prevalence. Observed injury patterns suggest targeted interventions including Nordic Hamstring Exercises and balance and proprioceptive training may decrease injury risk. Further research into this topic is needed to help reduce injury in these athletes.

\footnotetext{
a Corresponding Author:

Kevin J. Khoo, BS

1959 NE Pacific St.

Seattle, WA, 98195

khook@uw.edu.
} 
Table 1: Preseason and postseason survey information

\begin{tabular}{|c|c|}
\hline Preseason Survey Data & Postseason Survey Data \\
\hline $\begin{array}{l}\text { - Age } \\
\text { - Number of years playing Ultimate } \\
\text { - History of Ultimate-related injury } \\
\text { - Time missed due to injury during } 2018 \text { season } \\
\text { - History of Ultimate-related surgery } \\
\text { - Number of days/week participating in Ultimate, weight training, } \\
\text { and cross-training }\end{array}$ & $\begin{array}{l}\text { - Injury during } 2019 \text { season } \\
\text { - Time missed due to injury during } 2019 \text { season } \\
\text { - Number of days/week participating in Ultimate, weight training, } \\
\text { and cross-training }\end{array}$ \\
\hline
\end{tabular}

\section{Levels of Evidence}

Level 3.

\section{INTRODUCTION}

Ultimate Frisbee, or simply "Ultimate," is a rapidly growing non-contact sport played in all levels of competition in men's, women's, and coed divisions. In 2015, the Olympic Committee officially recognized Ultimate ${ }^{1}$, bringing it one step closer to inclusion in the Olympic Games. USA Ultimate reports an estimated seven million Ultimate players across 80 countries. $^{2}$ Despite this large player base, there is a lack of research on injury prevalence and risk. In a retrospective analysis of collegiate club sports injuries reported by a local sports clinic, Ultimate athletes had higher injury rates than other non-contact sports and comparable injury rates to rugby athletes. ${ }^{3}$ These findings suggest Ultimate athletes are at higher risk of injury, and specific aspects of Ultimate may increase the risk of injury relative to other non-contact sports. Two retrospective studies described injuries incurred in the Ultimate tournament setting, ${ }^{4,5}$ but no studies have described injury prevalence or identified injury risk factors during an elite club-level season.

The purpose of this study was to determine the prevalence of injuries among elite club-level men and women Ultimate Frisbee players and to identify elements associated with injury during a single season. This study focused on elite club-level players, which currently represents the highest level of competition in Ultimate.

\section{METHODS}

\section{DATA COLLECTION}

Preseason and postseason online surveys were designed by a single author to evaluate Ultimate players' demographics, lifetime Ultimate-associated injury/surgical history, current injury status, and other related elements (Table 1). This study was reviewed by the University of Washington Institutional Review Board and designated exempt.

Team captains of the top men's and women's club teams from a single geographic region were contacted to inform players of the nature of this study and their team's voluntary involvement. All members of teams contacted were at least 18 years of age, and each team had 28 players. The women's team had a member added prior to the season, resulting in a total 28 men and 29 women eligible to complete the preseason survey. The preseason online survey was distributed before the start of the 2019 season (May through October). After the completion of the season, which culminates in a national competition, the postseason online survey was distributed. The top coed team from the region was also asked to participate in the postseason survey, resulting in a total 42 men and 42 women eligible to complete the postseason survey.

\section{INJURY STATUS, SITE, AND SEVERITY}

Injury status was based on self-reported injuries, and players were considered injured if any injury was reported. Players also reported time missed during the 2018 or 2019 season due to injury (preseason and postseason surveys, respectively) and options included durations of N/A, <1 week, 1 week - 1 month, 1 month -3 months, and $>3$ months. In preseason surveys, athletes reported their lifetime Ultimate-associated injury history. In postseason surveys, athletes reported injuries sustained during the 2019 Ultimate season. Injuries were classified into one of three injury regions: upper extremity, lower extremity, and head/ neck/trunk. Injuries involving or distal to the hip joint were considered lower extremity injuries, injuries involving or distal to the shoulder joint were considered upper extremity injuries, and injuries to the head, neck, or trunk were categorized as head/neck/trunk injuries. During survey data compilation, players' descriptions of injury were used to verify appropriate categorization into the three injury regions.

\section{TRAINING REGIMEN}

Training was categorized into the following categories: Ultimate, cross-training, and weight-training. Players were asked to report the average number of days per week spent doing each type of training in the four weeks prior to completing the preseason and postseason surveys. Players' accumulated training was then determined by the sum of training days per week for all three categories. Ultimate training was defined as days per week of engaging in Ultimate play. Weight-training was defined as days per week engaging in weight training. Cross-training was defined as days per week spent doing any type of training other than playing Ultimate or weight-training. 
Table 2: Preseason and postseason comparisons by participation in various training programs

\begin{tabular}{|c|c|c|c|c|c|c|c|c|}
\hline & \multicolumn{4}{|c|}{ Preseason } & \multicolumn{4}{|c|}{ Postseason } \\
\hline & Men & Women & $\begin{array}{c}\mathrm{t}- \\
\text { value }\end{array}$ & $p$-value & Men & Women & $\begin{array}{c}\mathrm{t}- \\
\text { value }\end{array}$ & $p$-value \\
\hline $\begin{array}{c}\text { Average days/week playing } \\
\text { Ultimate }\end{array}$ & 2.7 & 2.4 & -0.48 & 0.63 & 3.2 & 2.4 & -2.05 & $0.047^{*}$ \\
\hline $\begin{array}{c}\text { Average days/week cross- } \\
\text { training }\end{array}$ & 4.1 & 3.4 & -0.95 & 0.35 & 1.9 & 2.2 & 0.69 & 0.5 \\
\hline $\begin{array}{c}\text { Average days/week weight- } \\
\text { training }\end{array}$ & 3.1 & 2.5 & -1.07 & 0.29 & 1.2 & 1.2 & -0.01 & 0.99 \\
\hline $\begin{array}{l}\text { Average accumulated training } \\
\text { days }\end{array}$ & 9.9 & 8.4 & -1.1 & 0.28 & 6.3 & 5.8 & -0.5 & 0.62 \\
\hline
\end{tabular}

\section{STATISTICAL ANALYSIS}

After the 2019 season, survey results were collected from the online survey host site and compiled in Microsoft ${ }^{\circledR}$ Excel 2010. All surveys completed were included for analysis. The sample correlation coefficient $(r)$ was used to determine linear correlations. Independent t-test comparisons were used when comparing means and $\chi^{2}$ comparisons were used when comparing proportions to determine statistically significant differences, using $p<0.05$ as a threshold for significance.

\section{RESULTS}

\section{DEMOGRAPHICS, TRAINING, SURVEY COMPLETION}

Of the 57 eligible athletes, 44 (77\%) completed the preseason survey. There were no statistical differences when comparing men and women in age (29.4 vs. $28.9, t=-0.41, p=$ 0.67 ), years of playing Ultimate (11.9 vs. $12.3, t=0.33, p=$ 0.76 ), or Ultimate-related surgical history (48\% vs. $40 \%, \chi 2$ $=0.25, p=0.62$ ). There were no statistical differences comparing men and women by training regimen (Table 2). Notably, preseason surveys were completed by 29 female players but only 15 male players (100\% vs. $54 \%, \chi 2=15.5, p=$ 0.0001).

Postseason surveys were completed by 23 female players and 18 male players (55\% vs. $43 \%, \chi 2=0.57, p=0.45$ ). Men reported playing Ultimate more days per week, on average, than women (3.2 vs. $2.4, t=-2.05, p=0.047)$ in the 4 weeks prior to completing postseason surveys. There were no other statistical differences between men and women regarding other training regimens (Table 2).

\section{PRESEASON INJURY SURVEY}

Preseason surveys showed 43 (98\%) players reported a previous Ultimate-related injury in their career, and 29 (66\%) players had previous Ultimate-related injuries in more than one injury region (Table 3 ). All players reporting previous Ultimate-related injury had an injury to their lower extremity. The most common injuries reported involved players' hamstrings (14), ankle (13), ACL (8), shoulder (14), and back (11). Other commonly reported Ultimate-related injuries suffered during a previous season are outlined in Table 4 . During the 2018 season, 39 (89\%) players missed some time due to injury, with 12 (27\%) players missing one month or longer (Table 3).

Women had a higher prevalence of previous foot injuries (31\% vs. $0 \%, \chi 2=5.7, p=0.017$ ), while men had a higher prevalence of ankle injuries ( $47 \%$ vs. $17 \%, \chi 2=4.4, p=$ $0.04)$. There were no other gender differences in previous injury prevalence. A larger proportion of men missed one week or more of the 2018 season due to injury compared to women (73\% vs. $31 \%, \chi 2=6.9, p=0.009)$ (Table 3 ).

There was a strong negative correlation between amount of time missed due to injury during the 2018 season and days per week spent weight training $(r=-0.92, p=0.026)$ (Figure 1) and accumulated training days $(r=-0.96, p=$ 0.01 ) (Figure 2) in the four weeks prior to players completing the preseason survey. There was a nonsignificant negative correlation between the amount of time missed during the 2018 season and days per week spent playing Ultimate $(r=-0.69, p=0.20)$ and cross-training $(r=-0.74, p=0.15)$ in the four weeks prior to players completing the preseason survey.

\section{POSTSEASON INJURY SURVEY}

Postseason surveys showed that 26 (63\%) players were injured during the 2019 season, with 23 (56\%) reporting a lower extremity injury and 8 (20\%) players reporting injuries in more than one injury region. The lower extremity was the most injured region, with hamstring (8), ankle (7), and back (3) injuries being the most common injuries reported. Other commonly reported injuries suffered during the 2019 season are outlined in Table 4 . A majority of players (63\%) reported missing some time during the season due to injury, and 5 (12\%) missed a month or longer (Table 3).

Compared to women, men had a higher prevalence of ankle ( $33 \%$ vs. $4 \%, \chi 2=5.9, p=0.01)$ and calf ( $17 \%$ vs. $0 \%$, $\chi 2=4.1, p=0.025)$ injuries. There were no other differences in injury prevalence by gender. There were no differences in time missed due to injury by gender during the 2019 season (Table 3). There were nonsignificant negative correlation sbetween amount of time missed due to injury during the 2019 season and days per week spent cross- 
Table 3: Injury history (preseason), injury occurrence (postseason), injury region, and time missed compared by sex

\begin{tabular}{|c|c|c|c|c|}
\hline \multicolumn{5}{|l|}{ Preseason } \\
\hline & Men (\%) & Women (\%) & Total (\%) & $p$-value \\
\hline History of Ultimate-related injury & $15 / 15(100)$ & $28 / 29(97)$ & $43 / 44$ (98) & 0.47 \\
\hline Lower Extremity & $15 / 15(100)$ & $28 / 29(97)$ & $43 / 44$ (98) & 0.47 \\
\hline Upper Extremity & $9 / 15(60)$ & $12 / 29(41)$ & $21 / 44(48)$ & 0.25 \\
\hline Head/Neck/Trunk & $4 / 15(27)$ & $10 / 29(34)$ & $14 / 44(32)$ & 0.6 \\
\hline \multicolumn{5}{|l|}{ Time missed during 2018 season: } \\
\hline none & $0 / 15(0)$ & $5 / 29(17)$ & $5 / 44(11)$ & 0.09 \\
\hline$<1 \mathrm{wk}$ & $4 / 15(27)$ & $15 / 29(52)$ & $19 / 44(43)$ & 0.12 \\
\hline $1 \mathrm{wk}-1 \mathrm{mo}$ & $5 / 15(33)$ & $3 / 29(10)$ & 8/44 (18) & 0.06 \\
\hline $1-3 \mathrm{mo}$ & $5 / 15(33)$ & $3 / 29(10)$ & 8/44 (18) & 0.06 \\
\hline$>3 \mathrm{mo}$ & $1 / 15(7)$ & $2 / 29(7)$ & $3 / 44(7)$ & 0.98 \\
\hline season & $0 / 15(0)$ & $1 / 29(3)$ & $1 / 44(2)$ & 0.47 \\
\hline \multicolumn{5}{|l|}{ Postseason } \\
\hline & Men (\%) & Women (\%) & Total (\%) & $p$-value \\
\hline Injured during 2019 season & $13 / 18(72)$ & $13 / 23(57)$ & $26 / 41(63)$ & 0.32 \\
\hline Lower Extremity & $11 / 18(61)$ & $12 / 23(52)$ & $23 / 41(56)$ & 0.58 \\
\hline Upper Extremity & $1 / 18(6)$ & $4 / 23(17)$ & $5 / 41(12)$ & 0.28 \\
\hline Head/Neck/Trunk & $4 / 18(22)$ & $4 / 23(17)$ & $8 / 41(20)$ & 0.7 \\
\hline \multicolumn{5}{|l|}{ Time missed during 2019 season: } \\
\hline none & 6/18 (33) & 9/23 (39) & $15 / 41(37)$ & 0.71 \\
\hline$<1 \mathrm{wk}$ & $4 / 18(22)$ & $5 / 23(22)$ & $9 / 41(22)$ & 0.97 \\
\hline $1 \mathrm{wk}-1 \mathrm{mo}$ & $5 / 18(28)$ & $7 / 23(30)$ & $12 / 41(29)$ & 0.86 \\
\hline $1-3 \mathrm{mo}$ & $3 / 18(17)$ & $2 / 23(9)$ & $5 / 41(12)$ & 0.44 \\
\hline$>3 \mathrm{mo}$ & $0 / 18(0)$ & $0 / 23(0)$ & $0 / 41(0)$ & N/A \\
\hline season & $0 / 18(0)$ & $0 / 23(0)$ & $0 / 41(0)$ & N/A \\
\hline
\end{tabular}

Table 4: Number and commonly reported injuries by injury region, $(\mathrm{n}=44$ preseason, $\mathrm{n}=41$ postseason)

\begin{tabular}{lcl}
\multicolumn{2}{l}{ Preseason Injury Survey } & \multicolumn{3}{l}{ Lifetime } & History of Ultimate-related Injury \\
& Total & Commonly Reported Injuries \\
Lower Extremity & 43 & Hamstring strain (14), ankle sprain (13), ACL tear (8) \\
Upper Extremity & 21 & Shoulder/rotator cuff injury (9), shoulder/AC dislocation (5) \\
Head/Neck/Trunk & 14 & Middle/lower back pain (11), concussion (1)
\end{tabular}

Postseason Injury Survey - Injury During 2019 Season $^{a}$

$\begin{array}{lll} & \text { Total } & \text { Commonly Reported Injuries } \\ \text { Lower Extremity } & 23 & \text { Hamstring strain (8), ankle sprain (7) } \\ \text { Upper Extremity } & 5 & \text { Shoulder/rotator cuff injury (1), shoulder impingement (1), lateral epicondylitis (1) } \\ \text { Head/Neck/Trunk } & 7 & \text { Middle back pain (3), concussion (1) }\end{array}$

training $(r=-0.73, p=0.27)$, weight training $(r=-0.28, p=$ $0.72)$, and accumulated training days $(r=-0.53, p=0.47)$ in the four weeks prior to players completing the postseason survey. There was a nonsignificant positive correlation between amount of time missed due to injury during the 2019 season and days per week spent playing Ultimate $(r=0.91$, 


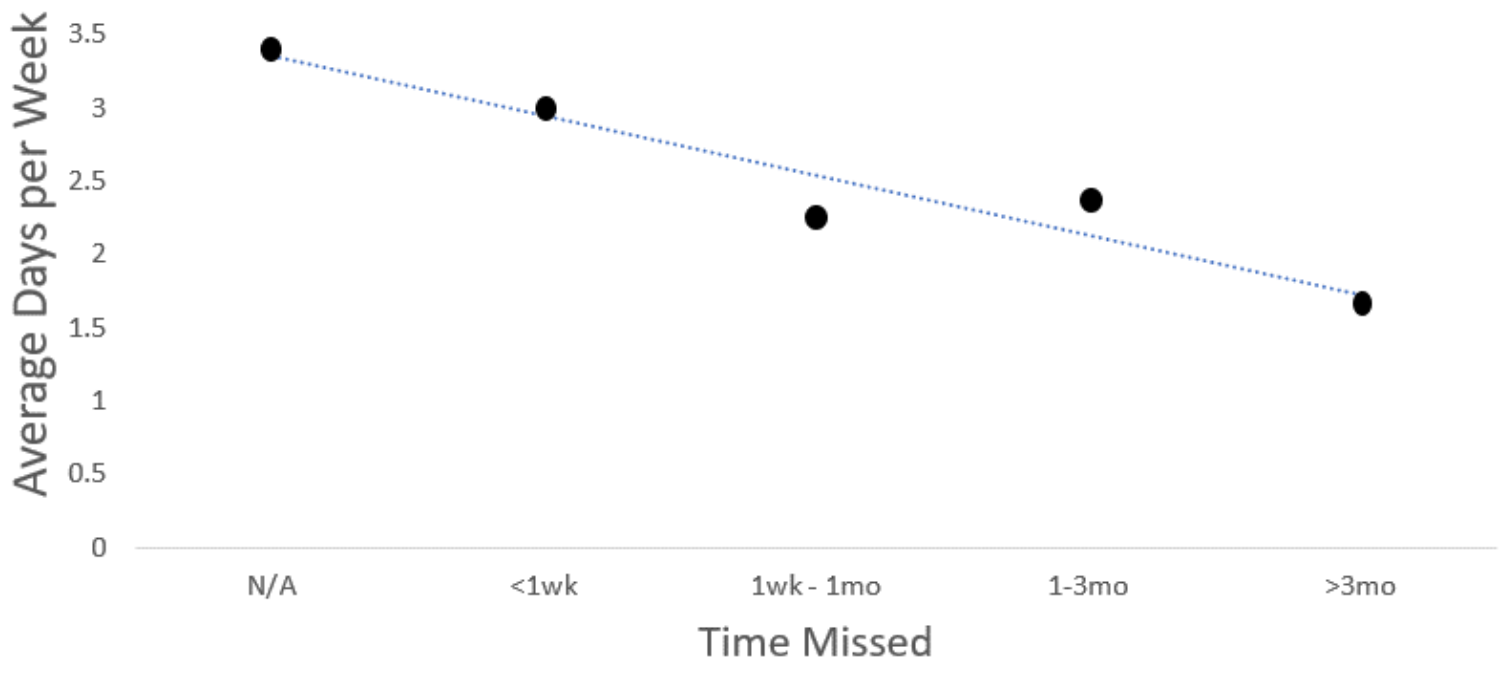

Figure 1: Time Missed During the 2018 Season vs Weight-training Regimen

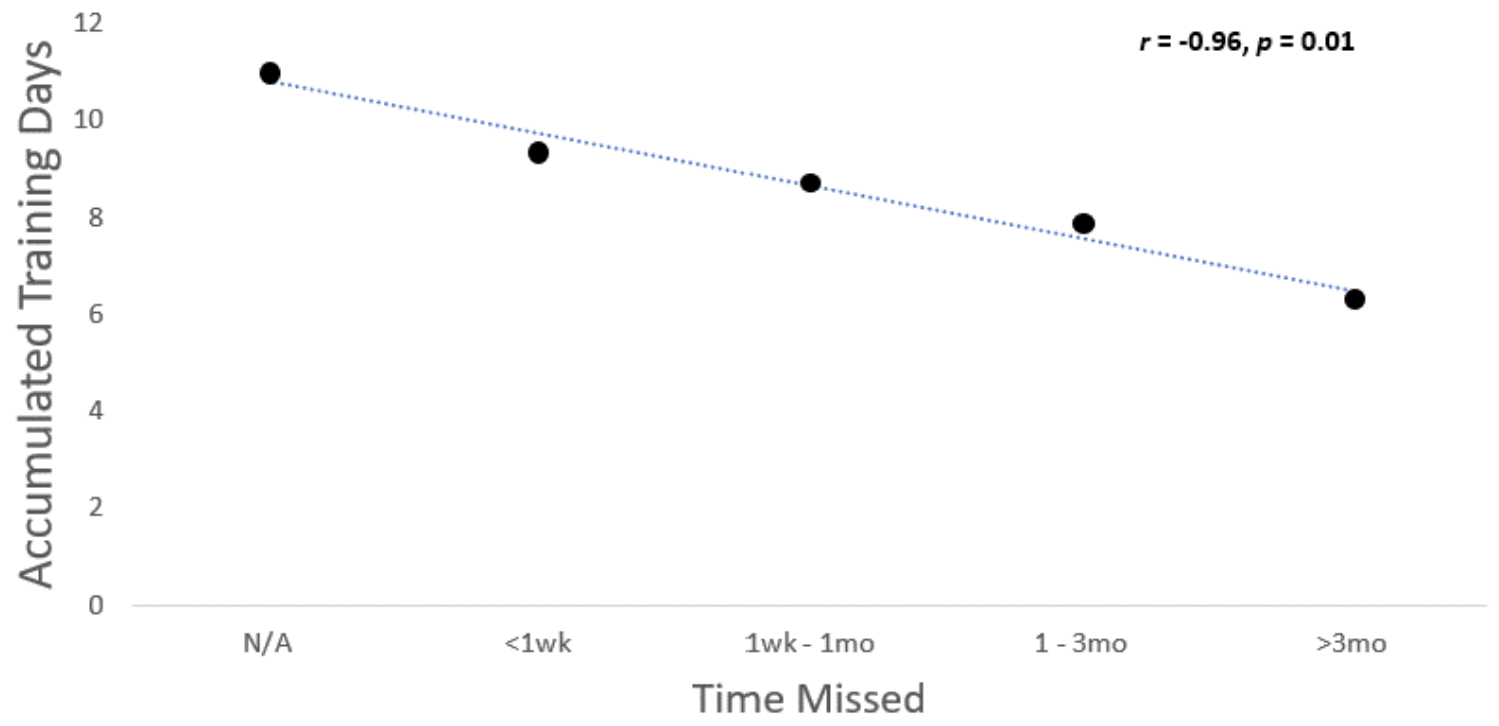

Figure 2: Time Missed During the 2018 Season vs Accumulated Training Days

$p=0.092)$ in the four weeks prior to completion of the 2019 postseason survey.

\section{DISCUSSION}

There was a high injury prevalence in the 2019 season, with 13 (57\%) women and 13 (72\%) men reporting injuries sustained during the season. Additionally, nearly all preseason respondents reported a history of injury while playing Ultimate, with 28 (97\%) women and 15 (100\%) men suffering a previous Ultimate-related injury. All 43 players reporting a lifetime history of Ultimate-related injury reported a previous lower extremity injury. As seen in other studies on Ultimate injuries, ${ }^{3-6}$ lower extremity injuries made up a large proportion of injuries during the 2019 season, with 12 (92\%) injured women and 11 (85\%) injured men reporting a lower extremity injury.

Thigh injuries were common in both men and women, largely represented by hamstring injury. Given the high hamstring injury prevalence, more emphasis should be placed on hamstring injury prevention. Incorporating Nordic Hamstring Exercises (NHE) in both amateur and professional soccer players' training regimen has been shown to reduce hamstring injury incidence. ${ }^{7-9}$ Given soccer and Ultimate players' similar in-game activity patterns like sprinting and cutting, the benefits seen in soccer players from NHE may translate to Ultimate players. FIFA $11+$ is a warmup program originally designed for injury prevention for soccer players ${ }^{10}$ that was subsequently found to reduce injury when implemented by elite male basketball play- 
ers. ${ }^{11}$ Similar to FIFA $11+$ 's success in basketball players, NHE's protective factors may translate to Ultimate players when incorporated into warmup and training regimens as a potential risk reduction tool.

Noteworthy differences in injury prevalence when comparing genders were men sustaining more ankle (33\% vs. $4 \%, \chi 2=5.9, p=0.01$ ) injuries than women. The high prevalence of ankle injuries in male Ultimate players suggests they may benefit from increased balance and proprioceptive training. ${ }^{12-17}$ Multiple studies have shown balance and proprioceptive training decreased the incidence and recurrence of ankle injuries in multiple sport populations, including soccer, basketball, and football, and this benefit may also translate to Ultimate players. Another factor that may be contributing to the high prevalence of lower extremity injury is the extensive history of previous lower extremity injury. Previous lower extremity injury has been shown to be an intrinsic risk factor for calf and hamstring injuries. ${ }^{18-20}$ Preseason survey results show 28 (97\%) women and 15 (100\%) men had a previous lower extremity injury, identifying this population as one that is implicitly at increased risk of calf and hamstring injury, and potentially contributing to the high lower extremity injury prevalence.

Due to field and player availability, Ultimate players frequently train for extended periods on weekend back-toback days. Additionally, players may see a sudden increase in play during weekend tournaments where they routinely have three to four games per day. Currently, it is unclear what effect, if any, this erratic pattern of training and competition has on players' injury risk. Chronic workload is defined as the average workload over a four-week $\operatorname{span}^{21}$ and previous studies have shown that both weight training 22,23 and increased chronic workload 24,25 have a protective effect on injury risk. In preseason and postseason surveys, chronic workload was approximated by calculating players' average accumulated training in the 4 weeks prior to completing a survey. Preseason survey results showed a strong negative correlation between time missed due to injury during the 2018 season and both players' reported weight training days per week $(r=-0.92, p=0.026)$ and accumulated training $(r=$ $-0.96, p=0.01)$. These results suggest that players who reported more weight training days per week and more accumulated training days missed less time due to injury. While this is consistent with previous studies demonstrating the protective effects of weight training and increased chronic workload, the interpretation of this observed correlation is unclear due to several limitations. The use of players' reported training regimen as approximations of their weight training or chronic workload is non-validated. Other limitations, including training duration and intensities being unstandardized and training days per week being self-reported by players, make it unclear how accurately reported training regimens represent a player's weight training or chronic workload prior to injury. Furthermore, postseason survey results did not redemonstrate this negative correlation, warranting cautious interpretation of this association. Nonetheless, these findings identify athlete workload monitoring as an important area of research to understand the relation between the unique training and competition patterns of Ultimate athletes and injury risk.
Preseason surveys revealed that only one (2\%) player reported a history of concussion while playing Ultimate, and postseason surveys found only one (2\%) concussion reported during the 2019 season, in contrast to a previous study reporting $26 \%$ of players acknowledged a concussion while playing Ultimate. ${ }^{26}$ One possible contributing factor to the lower number of concussions in the current study is the under-reporting of concussions. The previous study ${ }^{22}$ found only $80 \%$ of players believed they could recognize when they or a teammate sustained a concussion, indicating there is likely a subset of players who may incorrectly report not suffering a concussion. Additionally, the small sample size in this study may underrepresent the true prevalence of concussion in Ultimate players.

\section{LIMITATIONS}

This study used an online, voluntary survey and is implicitly limited by reporting bias. Additionally, low survey completion rates, particularly in the preseason male and postseason survey populations, limit the strength of study findings. Preseason and postseason survey results were not directly compared for reasons of limiting recall bias, different questions between surveys, and different subject groups completing the respective surveys due to the addition of the $3^{\text {rd }}$ local coed Ultimate team to the postseason survey group. The accuracy of some survey responses was another limitation. Injury classification was based on self-reported descriptions by players, without verification by a medical professional, making the accuracy of reported injuries unclear. Finally, the interpretation of players' training regimen and its relation to injury risk is uncertain due to several limitations. Days per week spent training was self-reported by players without standardization of intensity or duration necessary to qualify as a "day" of training, limiting conclusions that can be extrapolated by players' training regimens. Furthermore, due to this study's design, players' inseason training regimens prior to injury cannot be confidently determined, precluding a causal relationship between training regimen and injury. Lastly, the clinical significance of the observed correlation between time missed due to injury and training regimen in preseason results is unclear due to reasons previously described and warrants cautious interpretation. Despite these limitations, this is the first study to evaluate the prevalence of injury during an Ultimate season for both elite club-level men and women players and association with possible elements that may contribute to injury in this rapidly growing sport.

\section{CONCLUSION}

The results of the current study indicate that there was a high prevalence of self-reported injury among elite clublevel male and female Ultimate athletes during the 2019 season, with $88 \%$ of injured players reporting a lower extremity injury. Hamstring and ankle injuries were the most commonly reported lower extremity injuries, and men reported more injuries involving the ankle and calf than women. The high prevalence of hamstring and ankle injuries suggest that club-level Ultimate athletes may benefit from targeted interventions, including Nordic Hamstring 
Exercises, focused warm-up, and balance and proprioceptive training to decrease injury risk. Further research into injury in Ultimate players is needed to help reduce injury in these athletes.

\section{STATEMENT OF FINANCIAL DISCLOSURE AND CONFLICT OF INTEREST}

The authors have no financial disclosures or conflicts of interest.

Submitted: April 06, 2020 CDT, Accepted: October 10, 2020

CDT 


\section{REFERENCES}

1. World Flying Disc Federation Receives Recognition by the International Olympic Committee - WFDF. htt ps://wfdf.sport/2013/05/world-flying-disc-federationreceives-recognition-by-the-international-olympic-c ommittee/. Accessed February 8, 2021.

2. Ultimate U. USA Ultimate Annual Report 2017. http s://usaultimate.org/wp-content/uploads/2020/12/201 7AnnualReport_LR.pdf. Accessed February 8, 2021.

3. Akinbola M, Logerstedt D, Hunter-Giordano A, Snyder-Mackler L. Ultimate frisbee injuries in a collegiate setting. Int J Sports Phys Ther. 2015;10(1):75-84. http://www.ncbi.nlm.nih.gov/pubm ed/25709866. Accessed June 24, 2019.

4. Yen LE, Gregory A, Kuhn JE, Markle R. The Ultimate Frisbee Injury Study: The 2007 Ultimate Players Association College Championships. Clin J Sport Med. 2010;20(4):300-305. doi:10.1097/ISM.0b01 $\underline{3 e 3181 \mathrm{ea} 8 \mathrm{~b} 1 \mathrm{c}}$

5. Reynolds $\mathrm{KH}$, Halsmer SE. Injuries from ultimate frisbee. WMJ. 2006;105(6):46-49. http://www.ncbi.nl m.nih.gov/pubmed/17042420. Accessed June 25, 2019.

6. Marfleet P. Ultimate injuries: a survey. $\mathrm{Br} J$ Sports Med. 1991;25(4):235-240. doi:10.1136/bjsm.25.4.235

7. van der Horst N, Smits D-W, Petersen J, Goedhart EA, Backx FJG. The Preventive Effect of the Nordic Hamstring Exercise on Hamstring Injuries in Amateur Soccer Players: A Randomized Controlled Trial. Am J Sports Med. 2015;43(6):1316-1323. doi:10.1177/03635 $\underline{46515574057}$

8. Petersen J, Thorborg K, Nielsen MB, BudtzJørgensen E, Hölmich P. Preventive effect of eccentric training on acute hamstring injuries in men's soccer: A cluster-randomized controlled trial. Am J Sports Med. 2011;39(11):2296-2303. doi:10.1177/036354651 1419277

9. Al Attar WSA, Soomro N, Sinclair PJ, Pappas E, Sanders RH. Effect of Injury Prevention Programs that Include the Nordic Hamstring Exercise on Hamstring Injury Rates in Soccer Players: A Systematic Review and Meta-Analysis. Sport Med. 2017;47(5):907-916. $\underline{\mathrm{d}}$ oi:10.1007/s40279-016-0638-2

10. Bizzini M, Dvorak J. FIFA 11+: An effective programme to prevent football injuries in various player groups worldwide - a narrative review. $\mathrm{Br} \mathrm{J}$ Sports Med. 2015;49(9):577-579. doi:10.1136/bjsport s-2015-094765
11. Longo UG, Loppini M, Berton A, Marinozzi A, Maffulli N, Denaro V. The FIFA 11+ program is effective in preventing injuries in elite male basketball players: A cluster randomized controlled trial. Am J Sports Med. 2012;40(5):996-1005. doi:10.11 $\underline{77 / 0363546512438761}$

12. Mohammadi F. Comparison of 3 preventive methods to reduce the recurrence of ankle inversion sprains in male soccer players. Am J Sports Med. 2007;35(6):922-926. doi:10.1177/0363546507299259

13. Verhagen E, Van Der Beek A, Twisk J, Bouter L, Bahr R, Van Mechelen W. The effect of a proprioceptive balance board training program for the prevention of ankle sprains: A prospective controlled trial. Am J Sports Med. 2004;32(6):1385-1393. doi:10.1 $177 / 0363546503262177$

14. Schiftan GS, Ross LA, Hahne AJ. The effectiveness of proprioceptive training in preventing ankle sprains in sporting populations: A systematic review and meta-analysis. J Sci Med Sport. 2015;18(3):238-244. d oi:10.1016/j.jsams.2014.04.005

15. McGuine TA, Keene JS. The effect of a balance training program on the risk of ankle sprains in high school athletes. Am J Sports Med. 2006;34(7):1103-1111. doi:10.1177/036354650528419 1

16. McHugh MP, Tyler TF, Mirabella MR, Mullaney MJ, Nicholas SJ. The effectiveness of a balance training intervention in reducing the incidence of noncontact ankle sprains in high school football players. Am J Sports Med. 2007;35(8):1289-1294. doi:1 $\underline{0.1177 / 0363546507300059}$

17. Emery CA, Rose MS, McAllister JR, Meeuwisse $\mathrm{WH}$. A prevention strategy to reduce the incidence of injury in high school basketball: A cluster randomized controlled trial. Clin J Sport Med. 2007;17(1):17-24. do i:10.1097/JSM.0b013e31802e9c05

18. Green B, Pizzari T. Calf muscle strain injuries in sport: A systematic review of risk factors for injury. $\mathrm{Br}$ J Sports Med. 2017;51(16):1189-1194. doi:10.1136/bjs ports-2016-097177

19. Hauge Engebretsen A, Myklebust G, Holme I, Engebretsen L, Bahr R. Intrinsic risk factors for hamstring injuries among male soccer players: A prospective cohort study. Am J Sports Med. 2010;38(6):1147-1153. doi:10.1177/036354650935838 1 
20. Hägglund M, Waldén M, Ekstrand J. Risk factors for lower extremity muscle injury in professional soccer: The UEFA injury study. Am J Sports Med. 2013;41(2):327-335. doi:10.1177/0363546512470634

21. Bowen L, Gross AS, Gimpel M, Bruce-Low S, Li FX. Spikes in acute:chronic workload ratio (ACWR) associated with a 5-7 times greater injury rate in English Premier League football players: A comprehensive 3-year study. Br J Sports Med. 2019;54(12):731-738. doi:10.1136/bjsports-2018-0994 $\underline{22}$

22. Soligard T, Schwellnus M, Alonso J-M, et al. How much is too much? (Part 1) International Olympic Committee consensus statement on load in sport and risk of injury. Br J Sports Med. 2016;50(17):1030-1041. doi:10.1136/bjsports-2016-096581

23. Gabbett TJ. The training-injury prevention paradox: should athletes be training smarter and harder? Br J Sports Med. 2016;50(5):273-280. doi:10.1 136/bjsports-2015-095788
24. Hulin BT, Gabbett TJ, Lawson DW, Caputi P, Sampson JA. The acute: chronic workload ratio predicts injury: high chronic workload may decrease injury risk in elite rugby league players. Br J Sports Med. 2016;50(4):231-236. doi:10.1136/bjsports-201 5-094817

25. Hulin BT, Gabbett TJ, Caputi P, Lawson DW, Sampson JA. Low chronic workload and the acute:chronic workload ratio are more predictive of injury than between-match recovery time: A twoseason prospective cohort study in elite rugby league players. Br J Sports Med. 2016;50(16):1008-1012. doi:1 0.1136/bjsports-2015-095364

26. Lazar DJ, Lichtenstein JD, Tybor DJ. Concussion prevalence in competitive ultimate frisbee players. Orthop J Sport Med. 2018;6(3):2325967118759051. do i: $10.1177 / 2325967118759051$ 